\title{
RESIDUAL LIFE ASSESSMENT OF A PIPELINE BEND BY USING SMALL PUNCH CREEP TESTS
}

\author{
${ }^{1}$ Zdeněk KUBOŇ \\ ${ }^{1}$ MATERIÁLOVÝ A METALURGICKÝ VÝZKUM, Ostrava, Czech Republic, EU, \\ zdenek.kubon@mmvyzkum.cz
}

https://doi.org/10.37904/metal.2021.4151

\begin{abstract}
Small punch creep test (SPC test) is an alternative and still developing method to conventional uniaxial creep test and as such can be used for obtaining information about the creep properties of steels and alloys even when only a limited amount of test material is available. SPC method has been also implemented into EN 10371 "Metallic materials - Small punch test method". SPC testing can also be used with advantage also for assessment of the residual life of critical components of fossil fueled power plants. The biaxial nature of the SPC tests differs considerably from the uniaxial conventional creep tests but it is possible to convert the equivalent SPC loading to the uniaxial creep stress on the basis of the equal test durations. Such an approach is demonstrated on the material of a pipeline bend after long-term exposition at $490{ }^{\circ} \mathrm{C}$ and the results are used for the assessment of the residual lifetime of this bend made of a $0.5 \mathrm{Cr}-0.5 \mathrm{Mo}-0.3 \mathrm{~V}$ steel.
\end{abstract}

Keywords: Creep, SPC test, pipeline bend, creep rupture strength, residual life assessment

\section{INTRODUCTION}

The pressure parts of fossil fueled boilers are exposed during long-term operation to high temperature and pressure, which lead to the material degradation, i. e. changes in physical and mechanical properties and/or the damage of microstructure. Determination of the current material state and its properties and the associated estimation of residual life of a component using standardized testing procedures requires a large amount of test material and time-consuming shutdown associated not only with material sampling but also subsequent repair of the sampling point. Often, these places become the place of subsequent damage and/or cracks, during further operation. The small punch test method, which largely eliminates these hazards while maintaining an adequate level of accuracy and reliability, is becoming an increasingly exploited method for evaluating the degradation of material properties and determining the current mechanical properties of individual components of critical power plant components (yield strength, tensile strength, transition temperatures, fracture toughness, creep characteristics, etc.). National standards or binding guidelines already exist in Japan and the USA [1-2]. The European standard "Metallic materials - Small punch test method" was also issued in 2021 and covers the evaluation of mechanical properties by tensile testing from cryogenic to high temperatures and also deals with the estimation of creep characteristics based on the results of small punch tests [3].

The small punch test method was exploited in the case of determining material characteristics and residual lifetime assessment of a steam pipe bend made of $0.5 \mathrm{Cr}-0.5 \mathrm{Mo}-0.3 \mathrm{~V}$ steel and operated in a $110 \mathrm{MW}$ fossil fueled boiler at a temperature of $490-500{ }^{\circ} \mathrm{C}$ for more than 270,000 hours. Although the operating temperature of this steam pipeline is relatively low for the use of a given steel make (the maximum permissible temperature of this steel is up to $580^{\circ} \mathrm{C}$ ), a very long operating time does not exclude the possibility of appreciable degradation of its microstructure as well as the material properties. The evaluation of the actual material 
characteristic and mechanical properties and their influence on lifetime assessment of power plant components performed earlier [4] was supplemented by small punch creep testing.

\section{TESTED MATERIAL AND PROCEDURES}

The test material was scooped out at the extrados of the pipe bend in the form of three small samples using the SSam sampling device. After sampling, the edges of the sampling points were smoothed by grinding to avoid any structural notch. Thus, three disc-shaped samples were at disposal, on which it was possible to:

- $\quad$ perform control chemical analysis and to confirm the make of used steel,

- $\quad$ determinate the yield stress and tensile strength by small punch tests (SPT),

- $\quad$ perform hardness measurement,

- $\quad$ analyse the degradation of the microstructure (cavitation damage, degradation of the microstructure) including its evaluation according to VGB TW 507 [4],

- $\quad$ perform SPC tests at various loads and to calculate the residual lifetime.

\section{RESULTS OF ANALYSES OF CHEMICAL COMPOSITION AND MECHANICAL PROPERTIES}

The analysis of the chemical composition was performed on one of the small samples by X-ray spectrometry, the contents of carbon, sulfur and nitrogen by the combustion method on the LECO analyzer. The results are stated in Table 1 together with the nominal composition of the steel 15128 , the national equivalent steel grade in the Czech Republic [5].

Table 1 Chemical composition of pipeline elbow, mass $\%$

\begin{tabular}{|c|c|c|c|c|c|c|c|c|}
\hline Element & $\mathbf{C}$ & $\mathbf{S}$ & $\mathbf{M n}$ & $\mathbf{S i}$ & $\mathbf{P}$ & $\mathbf{C r}$ & Mo & V \\
\hline Sample & 0.15 & 0.016 & 0.57 & 0.20 & 0.014 & 0.60 & 0.41 & 0.28 \\
\hline Standard & $0.10-0.18$ & $\mathrm{max} .0 .040$ & $0.45-0.70$ & $0.15-0.40$ & $\max .0 .040$ & $0.50-0.75$ & $0.40-0.60$ & $0.22-0.35$ \\
\hline Element & $\mathbf{C u}$ & $\mathbf{T i}$ & $\mathbf{N b}$ & $\mathbf{A s}$ & $\mathbf{S b}$ & $\mathbf{S n}$ & $\mathbf{N}$ & $\mathbf{C E F}(-)$ \\
\hline Sample & 0.039 & 0.014 & $<0.003$ & 0.002 & $<0.001$ & 0.002 & 0.0120 & 0.034 \\
\hline
\end{tabular}

It is well known that the atoms of the substitution trace elements migrate to the grain boundaries, which results in embrittlement of the material. In order to evaluate the metallurgical quality of steel, a criterion of embrittlement susceptibility during long-term exposure, so-called CEF (Creep Embrittlement Factor), was formulated based on the concentration of phosphorus $(\mathrm{P})$, antimony $(\mathrm{Sb})$, tin ( $\mathrm{Sn})$ and arsenic (As) [6]:

$C E F=\% P+8.16(\% S b)+3.57(\% S n)+2.43(\% A s)$

Steels with values $C E F<0.15$ are considered to have a very good metallurgical quality. In the respective case, the value of $C E F$ was as low as 0.034 (see Table 1) and the steel thus has very low embrittlement susceptibility.

The mechanical properties of the bend were tested by small punch tests at room temperature. Disc-shaped test specimens with $8 \mathrm{~mm}$ in diameter and $0.5 \mathrm{~mm}$ thick were tested on INOVA 250 testing machine. The results are stated in Table 2, including the standardized values specified in the material standard for normalized and tempered state (grade 15128.5 ) and after accelerated cooling and tempering (grade 15 128.9). Hardness measurements were also performed on one of the small samples using the HV 10 method and the results of hardness measurements are summarized also in Table 2, altogether with the informative hardness of this steel stated in the material standard. It is evident that the mechanical strength of the pipe bend is high and lies above the standardized range for the steel grade 15128.5 and close to the maximum tensile strength 
valid for the grade 15 128.9. The same is true for the results of the hardness measurements. Also, this information confirms the assumptions of a very good condition of the bend material.

Table 2 Yield and tensile strength and hardness HV 10 at room temperature determined from SPT

\begin{tabular}{|c|c|c|c|c|}
\hline & $\mathbf{R}_{\mathrm{e}}(\mathrm{MPa})$ & $\mathbf{R}_{\mathrm{m}}(\mathrm{MPa})$ & $\mathbf{R}_{\mathrm{e}} / \mathbf{R m}(-)$ & HV $10(-)$ \\
\hline Sample 1 & 604 & 732 & 0.82 & $218,218,218$ \\
\hline Sample 2 & 736 & 760 & 0.97 & - \\
\hline 15128.5 [5] & $\min .365$ & $490-690$ & - & $147-208$ \\
\hline 15128.9 [5] & $\min .430$ & $570-740$ & - & $171-235$ \\
\hline
\end{tabular}

\section{RESULTS OF METALLOGRAPHIC ANALYSIS OF THE STEAM PIPELINE BEND}

Metallographic analysis was performed on a sample parallel to the sampling plane as well as to the pipe surface at the bend extrados and was concentrated in analysis of microstructure, evaluation of structural changes due to long-term exposure at high temperature and especially analysis of creep cavitation damage, including its evaluation according to VGB TW 507.

The microstructure of the steel consisted of ferrite with fine precipitates, blocks of tempered bainite and smaller dark islands, originally probably pearlitic, see Figure 1. The spheroidization of carbide particles in bainite or pearlitic lamellae was just starting and the secondary precipitates along the grain boundaries, which is the typical sign of structural degradation due to long-term high temperature exposure, were observed only very rarely, see Figure 2.

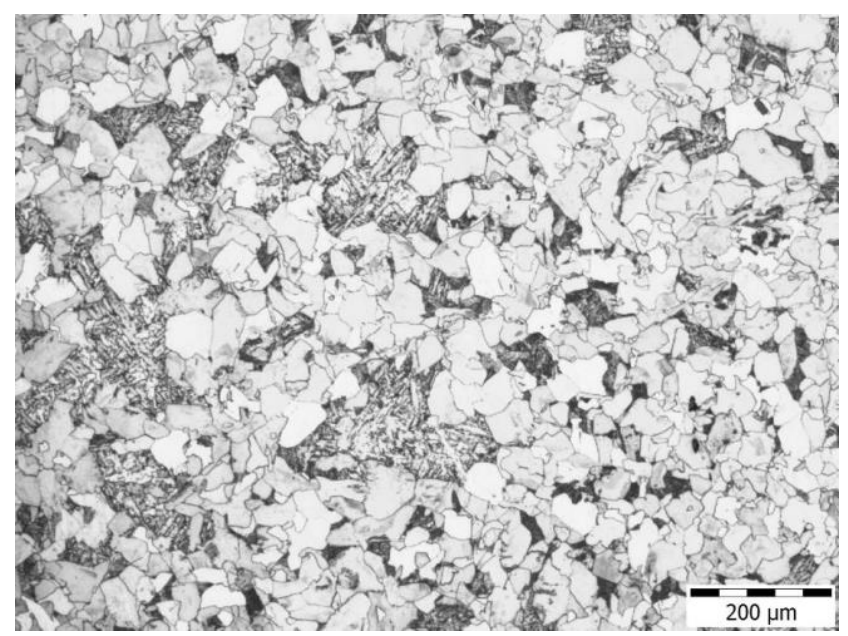

Figure 1 Microstructure of pipeline elbow

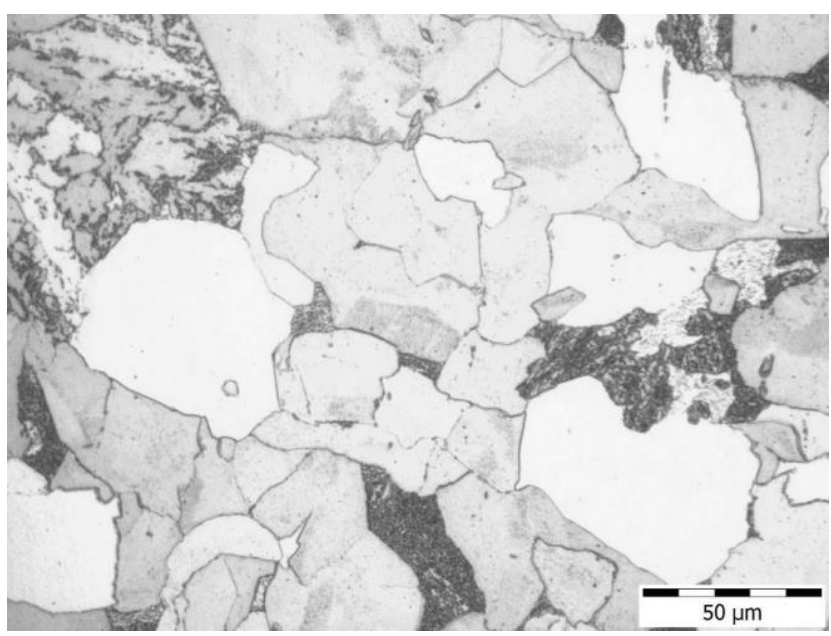

Figure 2 Detail of microstructure of pipeline elbow

Many methods based on evaluation of creep or cavitation damage are used worldwide to determine the safe life or at least the time period for re-evaluating the properties of high temperature components. Interpretation of observed structural damage requires an evaluation method based on a unique and clearly defined scale of damage. Currently, the most comprehensive and available rule is the German regulation VGB-TW 507, which provides images of reference microstructures for the entire range of creep damage in the most common heatresistant steels. VGB TW-507 applies to the original Neubauer distribution of damage classes [9], as shown in Table 3. The VGB TW- 507 also shows a complete set of micrographs of as received and creep-damaged state of materials for a wide range of different heat-resistant steels. Czech steel grade 15128 can be evaluated according to its equivalent, European steel 14MoV6-3 and the evaluation of creep cavitation damage of a 
sample taken from the steam pipeline bend corresponds to level 1: creep-exposed material without the occurrence of cavities.

Table 3 Description of Neubauer damage classes in VGB TW-507

\begin{tabular}{|c|c|c|}
\hline Damage class & Description of damage & Criterion \\
\hline 0 & As received material, without creep exposure & - \\
\hline 1 & Creep exposed material, without cavities & $N \leq 150$ cavities $/ \mathrm{mm}^{2}$ \\
\hline $2 \mathrm{a}$ & Advanced creep exposure, isolated cavities & $N>150$ cavities $/ \mathrm{mm}^{2}$ \\
\hline $2 \mathrm{~b}$ & Numerous cavities without preferred orientation & \\
\hline $3 a$ & Numerous cavities with directional orientation & 2 successive GB with at least 3 voids \\
\hline $3 b$ & Chains of cavities or grain boundaries separation & More than one GB length \\
\hline 4 & Microcracks & Cracks longer than 2 mm \\
\hline 5 & Macroscopic cracks & \\
\hline
\end{tabular}

\section{RESULTS OF SPC TESTS}

The method of SPC testing and evaluation of the test results are based on their correlation with the results of creep tests. Due to the complex stress state in SPC it is not possible to exactly transfer loading in SPC testing and stress in uniaxial creep tests. The evaluation of SPC results is usually based on correlation between results of the conventional uniaxial creep tests and SPC tests that compares load of SPC test $(F)$ and stress of the uniaxial creep tests $(\sigma)$ for the same temperature and time to rupture by the parameter $(\Psi)$ :

$\Psi=\frac{F}{\sigma}$

The value of the parameter $\Psi$ is usually in the range of about 1.2 to 2.5 for most steels. A program of SPC tests was performed at a temperature $600^{\circ} \mathrm{C}$ and at loads of $500,480,450,420,390,360$ and $330 \mathrm{~N}$. The results of this program are summarized in Table 4 and the results of individual tests are shown in Figure 3.

Table4 Results of SPC tests

\begin{tabular}{|c|c|c|c|}
\hline Temperature & Load & $\begin{array}{c}\text { Time to } \\
\text { rupture }\end{array}$ & $\begin{array}{c}\text { Deflection } \\
\text { rate }\end{array}$ \\
\hline$\left({ }^{\circ} \mathbf{C}\right)$ & $\mathbf{( N )}$ & $\mathbf{( h )}$ & $\left(\mathbf{m m}^{-1}\right)$ \\
\hline 600 & 500 & 74.5 & $1.3 \cdot 10^{-06}$ \\
\hline 600 & 480 & 49.2 & $1.0 \cdot 10^{-06}$ \\
\hline 600 & 450 & 241 & $4.9 \cdot 10^{-07}$ \\
\hline 600 & 420 & 99.5 & $8.5 \cdot 10^{-07}$ \\
\hline 600 & 390 & 135.8 & $6.5 \cdot 10^{-07}$ \\
\hline 600 & 360 & 273.8 & $4.9 \cdot 10^{-07}$ \\
\hline 600 & 330 & 398 & $3.1 \cdot 10^{-07}$ \\
\hline
\end{tabular}

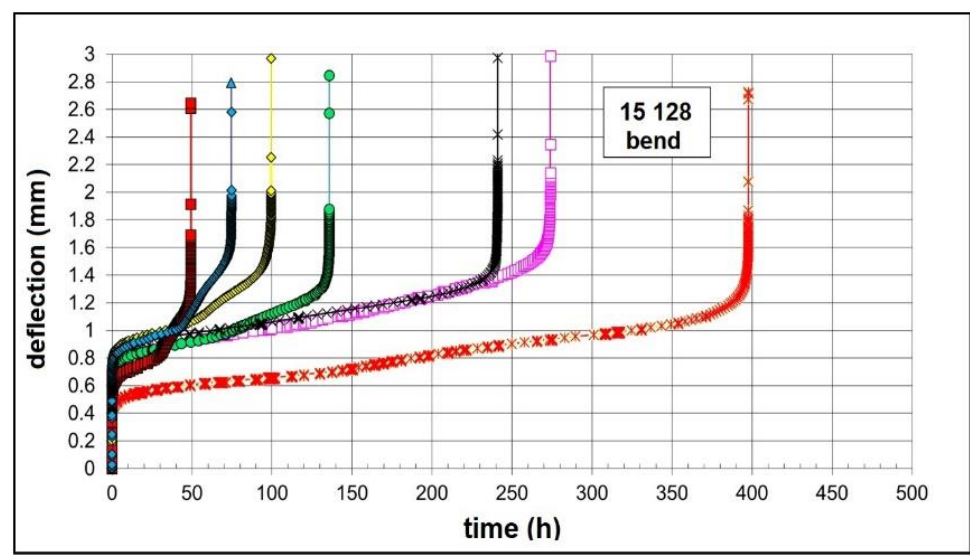

Figure 3 Results of SPC tests of steampipe bend

The Norton's creep power law was applied on the results of SPC tests in the form of:

$t_{r}=A_{S P} \cdot F^{-n_{S P}}$ 
where:

$t_{r}$ is time to rupture $(\mathrm{h})$

$F$ is the applied load $(\mathrm{N})$

$A_{S P}, n_{S P}$ are temperature dependent constants

For the extrapolation of the results of creep as well as SPC tests, the Larson-Miller parameter $P_{L M}$ is often exploited in the form:

$P_{L M}=T \cdot\left[C_{L M}+\log (t)\right]$

where:

$T$ is temperature $(\mathrm{K})$

$t$ is time to rupture $(\mathrm{h})$

$C_{L M}$ is Larson-Miller constant, in this case implicitly chosen at $\mathrm{C}=20$.

This parameterization of temperature and rupture time allows to influence the influence of both of these variables on one axis and thus perform make a direct comparison of creep tests performed at different temperatures.

The load dependence of timer to rupture calculated by Norton's equation is stated in Figure 4 and the relation of load versus Larson-Miller parameter in Figure 5.

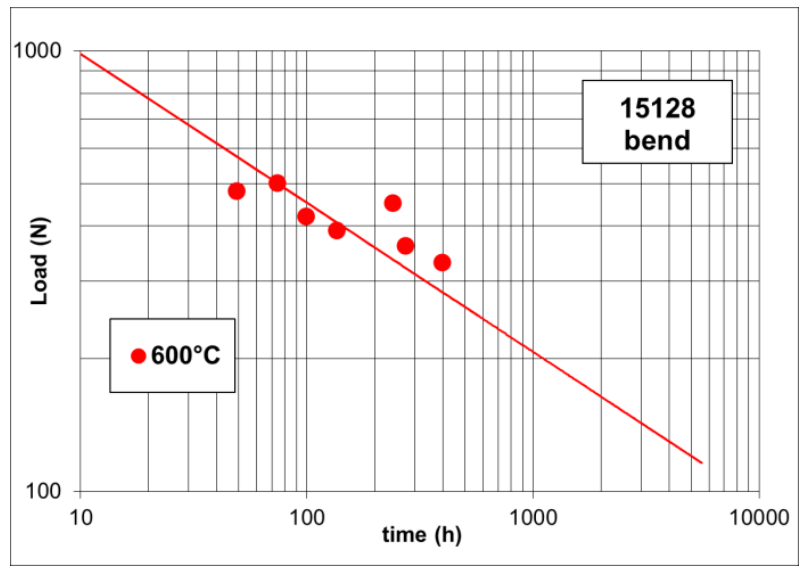

Figure 4 Correlation between loading and time to rupture

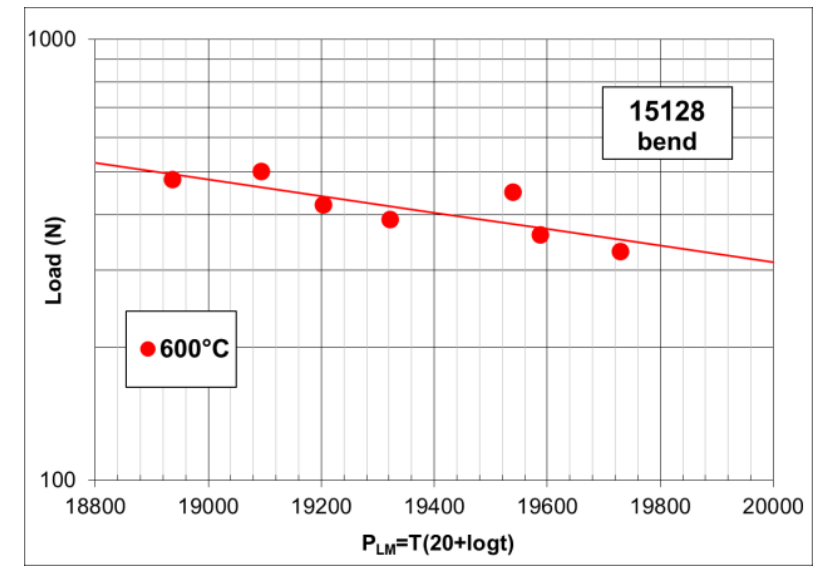

Figure 5 Correlation between time to rupture and L-M parameter

\section{APPLICATION OF RESULTS FOR RESIDUAL LIFE ASSESSMENT}

The hoop stress, which was determined for this bend by strength calculation of the pipeline taking into account the relaxation due to creep, is $142 \mathrm{MPa}$ and, when using the safety factor $\mathrm{k}=1.25$, the limit hoop stress is 177.5 MPa. When using the conversion coefficient $\Psi=2.1$ (see Equation (1)) determined in our creep laboratory for the conventional creep and SPC tests of this group of steels (low-alloy Cr-Mo-V steels), then the equivalent load to $177 \mathrm{MPa}$ for SPC test is $373 \mathrm{~N}$. Assuming the validity of the Larson-Miller equation compiled from the results of SPC tests in the whole considered temperature range, it is possible to convert the results obtained at a temperature of $600{ }^{\circ} \mathrm{C}$ to a working temperature, i.e. $490^{\circ} \mathrm{C}$. The results of this conversion are given in Table 5 for the load corresponding to the above operating stress.

Although the calculated time to rupture is very high, in principle it confirms the results of the other analyses, where both the strength properties as well as the microstructure corresponded to the as-received material without any creep exposition. This may be due to the fact that the operating temperature of the steam pipeline 
is relatively low for this steel grade that has a maximum working temperature up to $580^{\circ} \mathrm{C}$ and its most frequent applications are around $550^{\circ} \mathrm{C}$. If we take into account that the difference in temperature of about $30^{\circ} \mathrm{C}$ corresponds to the difference of one order of magnitude in the time to rupture, then the expected rupture time is not so high. In addition, thanks to the high values of yield stress and tensile strength, higher creep resistance can also be expected.

Table 5 Estimation of time to rupture by using Larson-Miller equation

\begin{tabular}{|c|c|c|}
\hline Load & \multicolumn{2}{|c|}{ Time to rupture (h) at temperature } \\
\hline$(\mathbf{N})$ & $600^{\circ} \mathrm{C}$ & $490^{\circ} \mathrm{C}$ \\
\hline 373 & 221 & 484700 \\
\hline
\end{tabular}

What is surprising, however, is the appearance of the microstructure of the steel in relation to its strength. This steel as of a $0.5 \% \mathrm{Cr}-0.5 \% \mathrm{Mo}-0.3 \% \mathrm{~V}$ type and with strength limit higher than $700 \mathrm{MPa}$ it should have a microstructure almost free of ferrite, which, however, does not correspond in the evaluated one. Its microstructure consists mainly of ferrite in combination with bainite and pearlite (see Figures 1 and 2). The possibility how to get such a high yield stress of steel with a ferritic-pearlitic or ferritic-bainitic microstructure is to use a low tempering temperature. The observed state of the microstructure allows this possibility, as does the high ratio of yield stress to tensile strength.

\section{CONCLUSION}

The small punch testing methods, including SPC tests, were used to perform the assessment of residual life of the steam pipeline bend after creep exposure for more than 270,000 hours at $490{ }^{\circ} \mathrm{C}$. The results of the analyses confirmed not only the high actual strength of the steam pipeline material, but also the very small extent of structural degradation due to long-term exposure at high temperature. Therefore, the estimated residual service life reached also hundreds of thousands of hours.

\section{ACKNOWLEDGEMENTS}

This paper was created in the frame of the Institutional support for long-term and conceptual development of a research organization in 2019, provided by the Ministry of Industry and Trade of the Czech Republic.

\section{REFERENCES}

[1] The Society of Materials Science. Standard for small punch creep test - estimation of residual life for high temperature component. Japan, 2012. ISBN 978-4-901381-38-3.

[2] ASTM E3205-20. Standard Test Method for Small Punch Testing of Metallic Materials. West Conshohocken, PA, USA: ASTM International, 2020.

[3] EN 10371. Metallic materials. Small punch test method. Brussels: CEN-CENELEC, 2021.

[4] KANDER, L., STEJSKALOVÁ, Š., ČížEK, P. Structure and Mechanical Properties of Austenitic Steels Affected by Sigma-Phase Precipitation due to Exposure to High Temperatures. Materiali in Tehnologije. 2018, vol. 52, no. 5, pp. 569-574

[5] VGB TW 507. Microstructure Rating Charts for Evaluating the Microstructure and Creep Damage of HighTemperature Steels for High-Pressure Piping and Boiler Components, 2nd Edition, Essen: VGB Powertech, 2005.

[6] ČSN 415128 . Ocel 15128 Cr-Mo-V. Praha: Úřad pro normalizaci a měření, 1984.

[7] BRUSCATO, R. Temper Embrittlement and Creep Embrittlement of 21/4Cr-Mo Shield metal Arc Deposits. Welding Journal. 1970, vol. 49(4), pp. 148-156.

[8] NEUBAUER B., WEDEL, V. Rest life estimation of creeping component by means of replication. In: Advances in life prediction. New York: ASME, 1983, pp. 317-324. 